\title{
EFFECT OF ACTIVATED CHARCOAL ADDITION ON FORMALDEHYDE EMISSION OF MEDIUM DENSITY FIBERBOARD
}

\author{
Saptadi Darmawan ${ }^{1,2}$, Kurnia Sofyan ${ }^{3}$, Gustan Pari ${ }^{4}$ and Krisdianto Sugiyanto ${ }^{4,5}$
}

\begin{abstract}
The manufacturing of medium density fiberboard (MDF) using dry forming process for interior purpose requires extensive amount of thermo-setting urea formaldehyde (UF) adhesive. Unfortunately, this adhesive brings about formaldehyde emission from the resulting MDF, which was potentially harmful to human beings. The use of activated charcoal can be effective to reduce such emission. As the relevance, this research aimed to investigate the effect of activated charcoal addition to the MDF pulp on formaldehyde emission from the MDF. The fibers for the MDF-mat forming were the pulp procured from the MDF factory, resulting from the thermo-mechanical pulping (TMP) conducted on the mixed mangium wood (Acacia mangium) and rubber wood (Hevea brasiliensis) in 3:1 (w/w) proportion, respectively. Such mixed TMP pulping was also done in the factory. The bonding between TMP pulp fiber during mat forming was assisted by the use of UF adhesive. Prior to the MDF mat forming, was added to the resulting TMP pulp-fibers activated charcoal in various amount, $2 \%, 4 \%$ and $6 \%$ based on fiber mass as well as based on UF adhesive mass. The activated charcoal was prepared by carbonizing candle nut shell into charcoal followed by activation process using phosphate solution. Meanwhile the forming of MDF mat employed air-dry process. As the control, MDF forming with UF adhesive was performed without addition of activated charcoal. It turned out that the activated charcoal-added MDF exhibited effective reduction in formaldehyde emission and significant improvement in physical and mechanical properties, i.e. lower thickness swelling, and greater MOR, MOE and internal bond, compared to the control MDF. The use of activated charcoal at $4 \%$ based on the adhesive mass seemed to be the optimum amount. Physical and mechanical properties of the activated charcoal added MDF could mostly meet the JIS specification.
\end{abstract}

Keywords: MDF, UF adhesive, candlenut shell, formaldehyde emission, activated charcoal, physical and mechanical properties

\section{INTRODUCTION}

Fiberboards that include hardboards, insulation boards, medium density fiberboards (MDF) belong to the category of engineered wood products, which are formed by at first breaking down wood into fibers. Afterwards, these fibers are reformed into a mat or the

\footnotetext{
${ }^{1}$ Forestry Research Institute of Mataram, Indonesia

${ }^{2}$ Corresponding Author. E-mail: saptadi_darma@yahoo.com

${ }^{3}$ Forestry Faculty of Bogor Agricultural Institute, Bogor, Indonesia

${ }^{4}$ Centre for Forest Product Research and Development, Indonesia

${ }^{5}$ School of Graduate Studies, The University of Melbourne, Australia
} 
so-called fiberboard using the media of water as well as air (wet and dry forming process, respectively). The bonding between fibers in the fiberboard mat can arise from the fiber material itself i.e. thermoplastic lignin. In order to improve the fiberboard properties (e.g. internal bonding strength, water resistance, decay resistance, fire resistance, etc), other materials can be added during mat forming or fiberboard finishing, such as thermosetting resin binder (adhesive), wax emulsion, preservative, and fiber retardants. The advantage of fiberboard is that it can be manufactured from low grade wood, small size wood, and residues (Walker, 1993). MDF is one of the fiberboard types which is commonly used in furniture manufacture and automotive industry to create free-form shapes such as dashboards, rear parcel shelves, and inner door shells.

Urea formaldehyde (UF) resin is predominantly used in MDF industry as it is thermosetting, low in cost, and fast curing characteristic. It is necessary to note that the UF adhesive is applied to reconstituted wood products, including also MDF, for interior use only. However, there is a public pressure on the use of UF resin due to their potential problem associated with the formaldehyde emission. In 2004, the Internal Agency for Research on Cancer (IARC) classified formaldehyde as harmful chemical for human body. Formaldehyde is classified into group 1 (carcinogenic to humans) which means a direct contact to formaldehyde can cause cancer to human body. Consequently, the use of formaldehyde on wood panels currently has been reduced to particular levels, previously regarded as not harmful to human health (World Health Organization, 2007).

Recently, to reduce formaldehyde emission in wood panel products, some studies have been carried out, such as the use of phenol-plastic, melamine and isocyanate adhesive (Santoso and Sutigno, 1998). However, most of those adhesives proposed were still high in costs and hence brought about impact on fiberboard productivity reduction as well as lowering of its physical and mechanical strength properties (Wang et al., 2004; Dynea, 2005).

Related with such, the use of activated charcoal is one of the possible methods to reduce formaldehyde emission (Pari et al., 2006; Park et al., 2006). Activated charcoal is a form of modified charcoal that has been further processed through the activation treatment to make it extremely porous thereby affording very large surface area available for adsorption or possibly chemical reaction. Judging from these phenomena, it is possible to incorporate the activated charcoal in the mixture of UF adhesive and fiber stuff for the manufacture of MDF with lower formaldehyde emission.

Candlenut shells are products from seed candlenut processing and so far they are still left unutilized. Therefore, those shells after being carbonized into charcoal and throughs the activation process, are potentially developed for high quality activated charcoal (Hendra and Darmawan, 2007). As the relevance, this paper aimed to investigate the effect of incorporation of activated candlenut shell charcoal in the mixture of UF adhesive and fibers at various proportions on properties and formaldehyde emission level of the resulting MDF. 


\section{MATERIALS AND METHODS}

\section{A. Materials}

The fiber materials for the MDF manufacture were obtained from the MDF factory in Karawang, West Java. The fiber resulted merely from the thermo-mechanical pulping (TMP) conducted on the mixed mangium wood (Acacia mangium) and rubber wood (Hevea brasiliensis) in 3:1 proportion, respectively (oven dried weight bases). Such mixed TMP pulping was already conducted in the factory as well.

Meanwhile, activated candlenut shell charcoal was prepared by at first carbonizing candlenut shells into charcoal, followed by activation by immersing the resulting charcoal in phosphate $\left(\mathrm{H}_{3} \mathrm{PO}_{4}\right)$ solution. The carbonization and activation were carried out in the Laboratory of Chemical Processing at the Center for Research and Development on Forestry Engineering and Forest Products Processing (CRDFEFPR), Bogor.

\section{B. MDF manufacture}

The TMP fibers for MDF were dried in the oven at a temperature of $60^{\circ} \mathrm{C}$ for about 24 hours to get $6-8 \%$ moisture content. The dried fibers were added in stages with UF adhesive (solid content $50 \%$ ), $\mathrm{NH}_{4} \mathrm{Cl}$ as catalyst, wax emulsion to enhance MDF water repellence, and finally activated candlenut shell charcoal to reduce formaldehyde emission. The amount of UF adhesive added weighed $12 \%$ of the total MDF mass, and the weights of $\mathrm{NH}_{4} \mathrm{Cl}$ and wax were $1 \%$ and $0.5 \%$ on adhesive mass, respectively. Meanwhile, activated candlenut charcoal as incorporated in the adhesive ingredients (UF and $\mathrm{NH}_{4} \mathrm{Cl}$ ) and fiber stuff varied in different amounts, i.e. consecutively $2 \%, 4 \%$ and $6 \%$, based on the adhesive mass and on the fiber mass, respectively (Table 1 ). In the first groups, the activated charcoals were added into the adhesive and then blended until homogeneous and sprayed on the fibers. Meanwhile in the second groups the activated charcoals were added into fibers stuffs and then blended until homogeneous, and these mixtures were sprayed with the adhesive (without activated charcoal). After being blended and then becoming homogeneous, the activated charcoals were shaped into MDF mat at the targeted dimension of $30 \mathrm{~cm} \times 30 \mathrm{~cm} \mathrm{x} 1 \mathrm{~cm}$ with a dry process and further compressed at $25 \mathrm{~kg} \mathrm{~cm}^{-2}$ in the elevated temperature $\left(160{ }^{\circ} \mathrm{C}\right)$ held for 10 minutes and were conditioned for one week. Prior to the tests on physical mechanical properties, and formaldehyde emission, all the resulting experimented MDFs were initially prepared into particular-size specimens and were condition for one week. 
Table 1. Mixture composition of the stuffs making up the MDF mat

\begin{tabular}{rlll}
\hline No. & Sample code & \multicolumn{1}{c}{ Mixture composition } & \multicolumn{1}{c}{ Activated charcoal amount } \\
\hline 1. & MDF control & MDF without activated charcoal & - \\
2. & MDF + A & MDF + activated charcoal & 2\% of adhesive mass added to adhesive \\
3. & $\mathrm{MDF}+\mathrm{B}$ & $\mathrm{MDF}+$ activated charcoal & $4 \%$ of adhesive mass added to adhesive \\
4. & $\mathrm{MDF}+\mathrm{C}$ & $\mathrm{MDF}+$ activated charcoal & $6 \%$ of adhesive mass added to adhesive \\
5. & $\mathrm{MDF}+\mathrm{D}$ & $\mathrm{MDF}+$ activated charcoal & 2\% of fiber mass added to fiber stuff \\
6. & $\mathrm{MDF}+\mathrm{E}$ & $\mathrm{MDF}+$ activated charcoal & $4 \%$ of fiber mass added to fiber stuff \\
7. & $\mathrm{MDF}+\mathrm{F}$ & $\mathrm{MDF}+$ activated charcoal & $6 \%$ of fiber mass added to fiber stuff \\
\hline
\end{tabular}

\section{Formaldehyde Emission Test}

In this experiment, formaldehyde emission was tested based on the method developed by Indonesian National Standard (SNI) test No. 01-7140-2005 for MDF (Badan Standardisasi Nasional Indonesia, 2005). The test was carried out using a desiccator method, whereby the MDF test pieces were placed in a desiccator containing a vessel into which was previously poured with distilled water, then left at $20^{\circ} \mathrm{C}$ for 24 hours. Afterwards, the formaldehyde as released from the test pieces would be absorbed by the distilled water forming formaldehyde solution. Further, formaldehyde concentration in the solution was determined photo-metrically.

\section{Physical and Mechanical Properties of MDF}

The tests on those MDF specimens were based on the Japanese Industrial Standard (Japanese Standard Association, 2003). Physical properties as tested included density, moisture content, thickness swelling, and water absorption. Meanwhile, the tested mechanical properties comprised modulus of rupture (MOR), modulus of elasticity (MOE), and internal bond (IB). In addition, scanning electron microscope (SEM) analysis was employed on MDF piece samples to visually examine, identify, and scrutinize the possible difference between surface profiles of the control MDF and of the activated charcoal incorporated MDF.

\section{E. Data Analysis}

Analysis on the data of formaldehyde emission, and physical and mechanical properties of MDF employed then so called completely randomized design (CRD) with one factor. The factor consisted of control MDF, and activated charcoal-incorporated MDF at various amounts of the charcoals (2\%, $4 \%$ and $6 \%$ of the adhesive mass added to the TMP fibers, and $2 \%, 4 \%$ and $6 \%$ of the TMP fiber mass for the MDF-mat). Each level of the factor was replicated three times. The related details about MDF composition is presented in Table 1. 


\section{RESULTS AND DISCUSSION}

\section{A. Formaldehyde Emission}

Generally, formaldehyde emission from MDF without activated charcoal (control) was higher than that from the activated charcoal incorporated MDF. On the first day of observation, the average emission level from the control MDF was $6.608 \mathrm{ppm}$, while the corresponding value for activated charcoal incorporated MDF varied between 4.417 and $6.426 \mathrm{ppm}$. Similarly, on the seventh day of observation, the average emission from the control was higher than that from the MDF incorporated (added) with activated charcoal. The results of formaldehyde emission from the MDF were presented in Table 2.

Table 2. Formaldehyde emission from the tested MDF

\begin{tabular}{clcccc}
\hline & & \multicolumn{2}{c}{ First day } & \multicolumn{2}{c}{ Seventh day } \\
\cline { 3 - 6 } No. & Sample code & $\begin{array}{c}\text { emission } \\
(\mathrm{ppm})\end{array}$ & $\begin{array}{c}\text { reduction } \\
(\%)^{*}\end{array}$ & $\begin{array}{c}\text { emission } \\
(\mathrm{ppm})\end{array}$ & $\begin{array}{c}\text { reduction } \\
(\%)^{*}\end{array}$ \\
\hline 1 & MDF control & 6.608 & - & 2.679 & - \\
2 & MDF + A & 5.701 & 13.73 & 2.534 & 5.41 \\
3 & MDF + B & 4.834 & 26.85 & 2.216 & 17.28 \\
4 & MDF + C & 4.417 & 33.16 & 2.066 & 22.88 \\
5 & MDF + D & 6.426 & 2.75 & 2.593 & 3.21 \\
6 & MDF + E & 5.913 & 10.52 & 2.528 & 5.64 \\
7 & MDF + F & 4.998 & 24.36 & 2.071 & 22.70 \\
\hline
\end{tabular}

Remarks: * percentage of reduction: by dividing the emission at particular level use of activated charcoal with the emission from the control MDF, than multiplied by $100 \%$

Analysis of variance using CRD revealed that formaldehyde emission level from activated charcoal incorporated MDF was significantly lower than that from the control (Figure 1 and Table 2). Such lowering was caused by the capability of the microstructure of the activated charcoal to adsorb formaldehyde in the MDF (Rong et al., 2002; Pari et al., 2006). In addition, the positively charged, base, and polar characteristics of the chemical compound in activated candlenut charcoal triggered the adsorption of the formaldehyde which is also polar. Further, the porous structure afforded greater surface area of the adsorbent (activated charcoal) and the holding of the adsorbate (formaldehyde) by activated charcoal through the secondary force of hydrogen bonding as well as Van Der Waals type. This enhanced the intimate take-up of adsorbate on the surface of adsorbent, thereby intensifying the adsorption of formaldehyde by the activated charcoal incorporated MDF. 


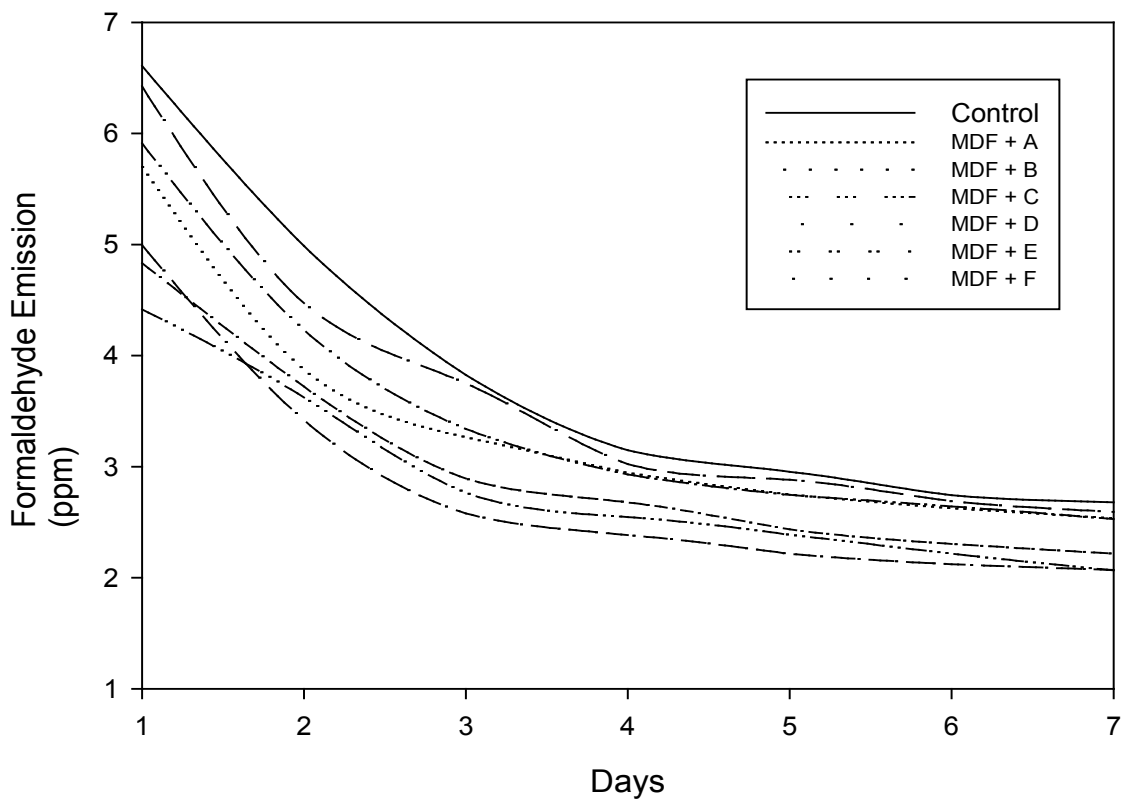

Figure 1. Formaldehyde emission from the tested MDF (For the designation of control, $\mathrm{MDF}+\mathrm{A}, \mathrm{MDF}+\mathrm{B}, \mathrm{MDF}+\mathrm{C}, \mathrm{MDF}+\mathrm{D}, \mathrm{MDF}+\mathrm{E}, \mathrm{MDF}+\mathrm{F}$, please refer to Table 1)

The percentage of emission reduction decreased exponentially along the observation day. Formaldehyde emission on the first day varied from 4.417 to 6.608 ppm, while the average emission on the seventh day was $2.35 \mathrm{ppm}$. The pattern model of emission reduction from the first day to seventh day was shown in Figure 1.

The initial formaldehyde emission was $6.608 \mathrm{ppm}$ in the control MDF and $5.382 \mathrm{ppm}$ in charcoal added MDF (average value). On the seventh day, the emission exponentially decayed to about $4 \mathrm{ppm}$ and then slightly decreased in the following 5 days. The decay graph of formaldehyde emission happened as MDF firstly was in contact with environment and the emission steadily decreased in exponential trend along the time i.e. days (Figure 1). This resulting phenomenon in fact corresponded to those of the previous researchers (Liteplo et al., 2002; Hawks and Hansen, 2002).

\section{B. Physical Properties}

In general, the MDF added with activated charcoal was darker in colour than the control MDF. For the comparison, the MDF added with activated charcoal in 
percentage based on fiber mass $(\mathrm{MDF}+\mathrm{D}, \mathrm{MDF}+\mathrm{E}, \mathrm{MDF}+\mathrm{F})$ exhibited darker color than that based on adhesive mass $(\mathrm{MDF}+\mathrm{A}, \mathrm{MDF}+\mathrm{B}, \mathrm{MDF}+\mathrm{C})$, as shown in Figure 2. This is reasonable since in quantity the amount of activated charcoal in the former MDF was greater than that on the latter MDF.

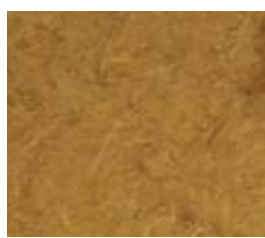

a

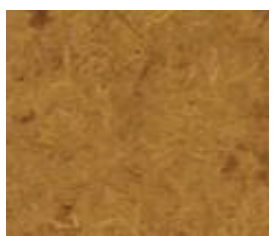

b

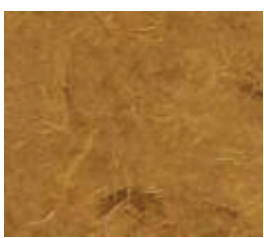

c

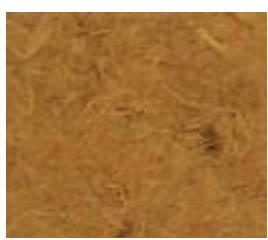

d

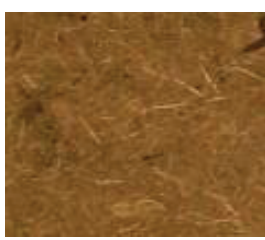

e

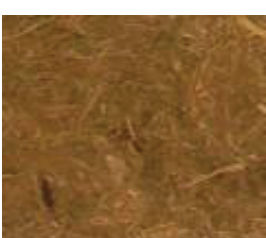

f

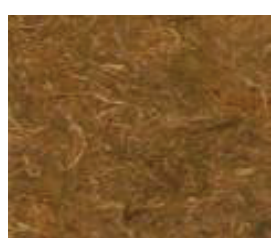

$\mathrm{g}$

Remarks : $\mathrm{a}=$ Control, $\mathrm{b}=\mathrm{MDF}+\mathrm{A}, \mathrm{c}=\mathrm{MDF}+\mathrm{B}, \mathrm{d}=\mathrm{MDF}+\mathrm{C}, \mathrm{e}=\mathrm{MDF}+\mathrm{D}, \mathrm{f}=\mathrm{MDF}+\mathrm{E}, \mathrm{g}=$ $\mathrm{MDF}+\mathrm{F}$

Figure 2. Visual observation: the surface of MDF

Physical properties of MDF samples tested were shown in Table 3. In general, based on results of analysis of variance, the physical properties of the control MDF did not differ from those of activated charcoal incorporated MDF except for water absorption. The entire density of MDF varied about $0.35-0.80 \mathrm{~g} \mathrm{~cm}^{-3}$. Likewise, moisture contents of the control MDF and activated charcoal added MDF were not significantly different from each other. The moisture content, varied from 8.26 to $9.17 \%$. Moisture content and density of the overall MDF could meet the JIS specification (Table 3 ). 
Table 3. Physical properties of the tested MDF

\begin{tabular}{clcccc}
\hline No. & Sample code & $\begin{array}{c}\text { Density } \\
\left(\mathrm{g} \mathrm{cm}^{-3}\right)\end{array}$ & $\begin{array}{c}\text { Moisture } \\
\text { content } \\
(\%)\end{array}$ & $\begin{array}{c}\text { Thickness } \\
\text { swelling } \\
(\%)\end{array}$ & $\begin{array}{c}\text { Water } \\
\text { absorption } \\
(\%)\end{array}$ \\
\hline 1 & MDF control & 0.77 & 8.43 & 7.53 & 14.46 \\
2 & MDF + A & 0.78 & 8.26 & 5.83 & 14.42 \\
3 & MDF + B & 0.77 & 8.41 & 4.84 & 14.39 \\
4 & MDF + C & 0.76 & 8.45 & 4.60 & 14.38 \\
5 & MDF + D & 0.78 & 8.25 & 5.51 & 17.80 \\
6 & MDF + E & 0.77 & 8.72 & 6.06 & 19.68 \\
7 & MDF + F & 0.76 & 9.17 & 6.63 & 20.91 \\
8 & JIS & $0.35-0.80$ & $5-13$ & $<12.00$ & - \\
\hline
\end{tabular}

$\left({ }^{*}\right)$ Source : Japanese Standard Association (2003)

Addition of activated charcoal to MDF caused significant differences in thickness swelling and water absorption in comparison with those of control MDF. In general, the activated charcoal added MDF exhibited lower thickness swelling than that of control MDF (Table 3). The possible explanation was with the incorporation of activated

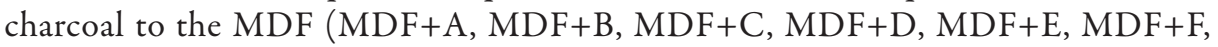
as described in Table 1), therefore, the mass portion of fibers in the activated charcoaladded MDF for its particular volume $(30 \mathrm{~cm} \times 30 \mathrm{~cm} \times 1 \mathrm{~cm})$ decreased and become lower than that of the control MDF. Consequently, the capability of such MDF to swell its fiber following water-immersion decreased, thereby exhibiting lower thickness swelling.

With respect to water absorption, the situation in the activated charcoal-added MDF (particularly at the charcoal of $2 \%, 4 \%$, and $6 \%$ based on fiber mass) was on the contrary to that in the control MDF. In this way, the thickness swelling in the former MDF was significantly lower than in the latter MDF (control), but the water absorption exhibited the reverse (Table 3). The explanation was that greater water absorption in the activated charcoal added MDF was mostly brought about by the porous characteristics and surface tension inside the structure of charcoal itself, thereby not contributing much to the MDF thickness swelling. It is interesting to note that all this resulting phenomena were consistent with those from the previous study (Kim and Lee, 2003). The water absorption and the thickness swelling of the overall MDF (with and without activated charcoal addition) varied about consecutively $14.4-20.9 \%$ and $4.6-7.5 \%$, and the later value were still comparable to the swelling required by JIS (Table 3 ). 


\section{Mechanical Properties}

Mechanical properties of the tested MDF are shown in Table 4. Modulus of rupture (MOR) of MDF varied about 241-365 $\mathrm{kg} \mathrm{cm}^{-2}$, whereby the MOR of the activated charcoal added MDF was mostly higher than that of the control MDF. The highest MOR was achieved by the MDF added with charcoal at $4 \%$ based on adhesive mass $(\mathrm{MDF}+\mathrm{B})$, while the lowest exhibited by that at $6 \%$ based on fiber mass $(\mathrm{MDF}+\mathrm{F})$.

Modulus of elasticity (MOE) of activated charcoal added MDF was higher than that of the control MDF except for those designated as MDF+D and MDF+F (Table 4). The highest MOE was achieved by the MDF added with activated charcoal at $4 \%$ based on adhesive mass $(\mathrm{MDF}+\mathrm{B})$, while the lowest gained by that of $6 \%$ based on fiber mass $(\mathrm{MDF}+\mathrm{F})$. Likewise, internal bond (IB) of activated charcoal added MDF was higher than that of the control MDF, except for those designated as MDF+C and MDF+F.

Table 4. Mechanical properties of the tested MDF

\begin{tabular}{rlccc}
\hline No. & Sample code & $\begin{array}{c}\text { Modulus of rupture } \\
\left(\mathrm{kg} \mathrm{cm}^{-2}\right)\end{array}$ & $\begin{array}{c}\text { Modulus of elasticity } \\
\left(\mathrm{kg} \mathrm{cm}^{-2}\right)\end{array}$ & $\begin{array}{c}\text { Internal bond } \\
\left(\mathrm{kg} \mathrm{cm}^{-2}\right)\end{array}$ \\
\hline 1 & MDF control & 222 & 27,533 & 3.54 \\
2 & MDF + A & 319 & 30,709 & 5.68 \\
3 & MDF + B & 365 & 34,797 & 5.15 \\
4 & MDF + C & 309 & 30,009 & 2.51 \\
5 & MDF + D & 250 & 26,387 & 4.14 \\
6 & MDF + E & 323 & 28,068 & 7.57 \\
7 & MDF + F & 241 & 23,319 & 3.26 \\
8 & JIS & $>153$ & $>13,260$ & $>3.06$ \\
\hline
\end{tabular}

$\left({ }^{*}\right)$ Source : Japanese Standard Association (2003)

Judging from the test results on those three mechanical properties of MDF (MOR, MOE, and IB), it can be inferred that the MDF with less amount of charcoal addition mostly exhibited higher strength than the control MDF and the MDF with the greater amount of added charcoal. This was explainable that the incorporation of activated charcoal in the MDF, which was positively changed and polar, filled up the void space between fibers in the MDF thereby intensifying the intimate contact of fiber-charcoalfiber system and hence enhancing the hydrogen bond and Van Der Waals force in the system. In this way, therefore, the strength property of the activated charcoal added MDF was significantly improved. However, too much addition of activated charcoal to the fiber stuffs, such as the case of $\mathrm{MDF}+\mathrm{D}, \mathrm{MDF}+\mathrm{E}$, and $\mathrm{MDF}+\mathrm{F}$ (Table 4) could cause the negative interfere of the contact bonding between TMP fibers during MDF mat forming, and this explained why the strengths of MDF with greater amount of 
added charcoal were lower those with less amount of charcoal. Further, the MOR, MOE, and IB of the experimented MDF (with and without activated charcoal addition) could mostly comply with those required by the JIS (Table 4).

Scanning electron microscopic (SEM) analysis on the surface of activated charcoal added MDF indicated that there were still more frequent void spaces between fibers compare to the MDF with greater amount of added charcoal (Figure 3). Meanwhile, the control MDF exhibited the most frequent void spaces. This hinted that the particles of activated charcoal filled up the gap or empty spaces between fibers in the MDF. This again confirmed that this situation contributed to the strength improvement (MOR, MOE, IB) of charcoal added MDF, particularly for the cases of MDF+A, MDF+B, and $\mathrm{MDF}+\mathrm{C}$ (Table 4).
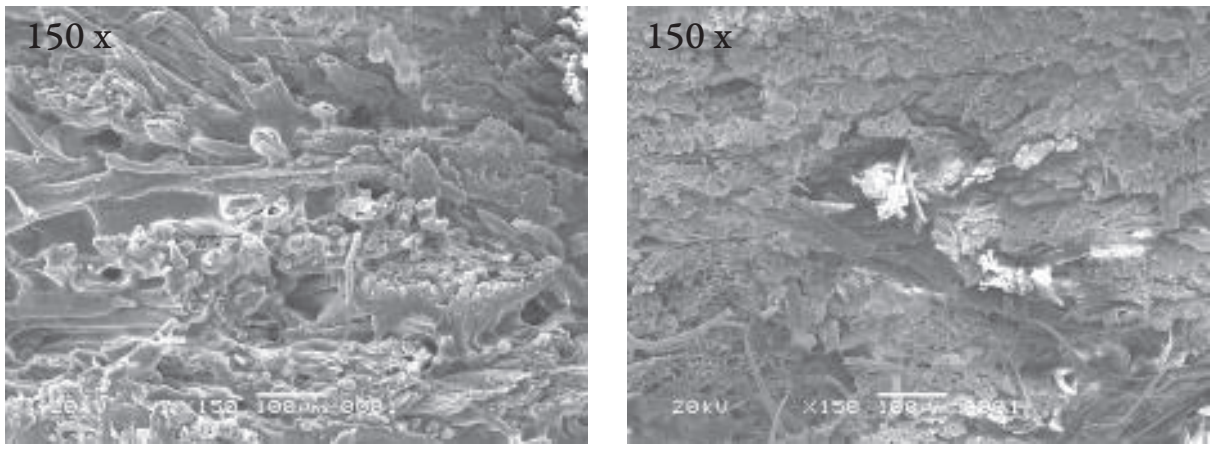

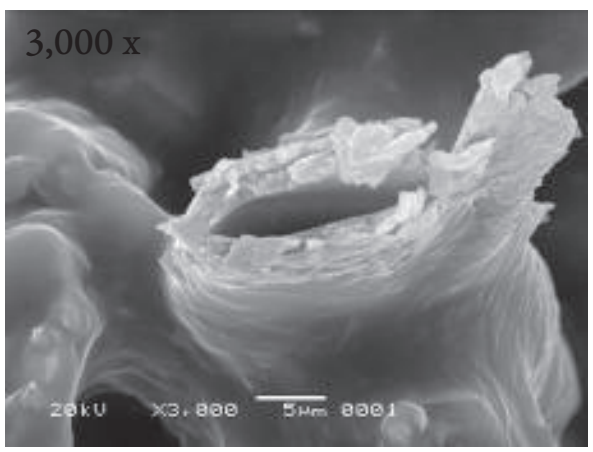

a

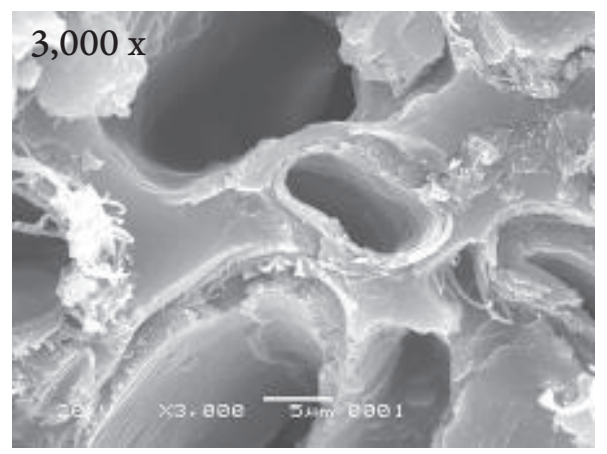

b

Remarks : $\mathrm{a}=$ Control MDF; $\mathrm{b}=\mathrm{MDF}+\mathrm{D}$

Figure 3. SEM analysis on the surface of MDF samples 


\section{CONCLUSION}

Formaldehyde emission from the MDF was significantly reduced by adding the activated charcoal to the UF (urea formaldehyde) adhesive and fiber stuff, prior to the MDF mat forming. The reduction percentage of formaldehyde emission from the activated charcoal added MDF ranged about 2,75-33,16\%, compared to that of the control MDF (0\%). That percentage increased by adding the activated charcoal in higher number. Visual observation on the MDF surface revealed that the activated charcoal added MDF was darker in color than that of the control MDF.

The addition of activated charcoal did not bring about significant differences in the moisture content and density among the resulting MDF. However, it affected the thickness swelling and water absorption. As such, thickness swelling of activated charcoal added MDF was lower than that of the control MDF. Meanwhile, significant increase in water absorption occurred to the MDF added with activated charcoal particularly at the percentage based on fiber mass. Physical properties of the overall MDF (with or without activated charcoal), i.e. density, moisture content, thickness swelling and water absorption could mostly meet the JIS specification.

Modulus of rupture (MOR) of charcoal added MDF varied about 241-365 kg cm${ }^{-2}$, which was higher than that of control MDF. This situation also occurred mostly to modulus of elasticity/MOE $\left(23,319-34,797 \mathrm{~kg} \mathrm{~cm}^{-2}\right)$ and internal bond/IB (3.26-7.57 $\mathrm{kgcm}^{-2}$ ) of the charcoal added MDF. Most of mechanical properties of the overall MDF (MOR, MOE, and internal bond/IB) of the overall MDF could comply with the JIS specification.

Scanning electron microscopic (SEM) analysis on the MDF surface indicated that there were more void spaces between fiber in the control MDF than those in the activated charcoal-added MDF. This SEM analysis exhibited that the addition of charcoal brought about the filling-up of such void spaces in the MDF.

\section{REFERENCES}

Badan Standarisasi Nasional Indonesia. 2005. Emisi formaldehida pada panel kayu. Standard Nasional Indonesia (SNI) No. 01-7140-2005. Badan Standarisasi Nasional Indonesia. Jakarta.

Dynea. 2005. Resin for ultra low formaldehyde emission according to the Japanese $\mathrm{F}^{* * * *}$ quality. San Diego. Manfred Dunky.

Hawks, L.K., and A.B. Hansen. 2002. Formaldehyde. Utah University Extension. Electronic Publishing. http://www.utah.ac. Downloaded at 27 March 2007.

Hendra, D., dan S. Darmawan. 2007. Sifat arang aktif tempurung kemiri. Jurnal Penelitian Hasil Hutan 25(4): 291-302. (in Indonesian with English abstract). 
Japanese Standard Association. 2003. Fiberboards, Japan industrial standard No. A 5905. Japanese Standard Association.

Kim, G.E. and H.H. Lee. 2003. Properties of charcoal-fiber board by wet forming process. International Conference on Forest Products Better Utilization of Wood for Human, Earth and Future Vol.2. Proceedings of the IAWPS.

Liteplo, R.G., R. Beauchamp, M.E. Meek, and R. Chenier. 2002. Formaldehyde. Concise International Chemical Assessment Document 40. Geneva. WHO. 75p.

Pari G., S. Kurnia, S. Wasrin and Buchari. 2006. Tectona grandis activated charcoal as catching agent of formaldehyde on plywood glued with urea formaldehyde. Proceedings of the $8^{\text {th }}$ Pacific Rim Bio-Based Composites Symposium. Kuala Lumpur. Malaysia.

Park, S.B., K. Su-Won, P. Jong-Young and R. Jung-Kwan. 2006. Physical and mechanical properties and formaldehyde emission of particleboard with bamboo charcoal. Journal of Forest Science 69: 50-59.

Rong, H., Z. Ryu., J. Zheng and Y. Zhang. 2002. Effect of air oxidation of rayon-based activated carbon fibers on the adsorption behaviour for formaldehyde. Carbon 40: 2291-2300.

Santoso, A and P. Sutigno. 1998. Several factors affecting the formaldehyde emission from wood-based panels. Proceedings the fourth Pacific Rim Bio-Based Composites Symposium. Bogor, Indonesia.

Walker, J.C.F. 1993. Wood panels: particleboards and fiberboards. In: Walker, J.C.F. Primary Wood Processing. Principles and Practice. Chapman and Hall, London.

Wang, W., X. Zang and R. Lu. 2004. Low formaldehyde emission from particleboard bonded by UF-MDI mixture adhesive. Forest Product Journal 54(9): 36-39.

World Health Organization. 2007. Prevention cancer control: knowledge into action: World Health Organization (WHO) guide for effective programmes: module 2). Switzerland. 